\title{
THE USE OF CANINE MESENCHYMAL STEM CELLS FOR THE AUTOLOGOUS TREATMENT OF OSTEOARTHRITIS
}

\author{
Sanja SRZENTIĆ DražILOV ${ }^{1}$, Janko MrKOVAČKI ${ }^{2}$, Vesna SPASOVSKI ${ }^{1}$, Amira FAZLAGIĆ $^{3}$, \\ Sonja PAVLOVIĆ ${ }^{1}$ and Gordana NiKČEVIĆ ${ }^{1 *}$ \\ ${ }^{1}$ Laboratory for Molecular Biomedicine, Institute of Molecular Genetics and Genetic \\ Engineering, University of Belgrade, Vojvode Stepe 444a, P.O. Box 23, 11010 Belgrade, \\ Serbia; ${ }^{2}$ Stem Art Ltd., Belgrade, Serbia; ${ }^{3}$ National Association for the Improvement and \\ Development of Regenerative Medicine, Belgrade, Serbia
}

(Received 12 December 2017; accepted 25 July 2018)

\begin{abstract}
Mesenchymal stem cells (MSCs) hold enormous potential for cell-based therapy in the treatment of various diseases, particularly those which currently cannot be cured and result in poor outcomes or invasive surgery. Here we present results of the application of autologous, culture-expanded, adipose tissue (AT)derived MSCs for the osteoarthritis (OA) treatment of 10 canine patients. The stemness of isolated cells has been confirmed by their ability to differentiate into osteo- and chondrocytic lineages. The clinical effect of a single injection of ATMSCs into the symptomatic joints was evaluated by a veterinarian for five disabilities characteristic of OA at 30,60 and 90 days after treatment, which has been designated as the initial evaluation period. Functional outcomes for all analysed characteristics improved significantly at the end of this evaluation compared with the baseline. In addition, for 5 of these 10 patients, an extended follow-up study was performed from 1 to 4 years after the initial evaluation period. We detected long-lasting positive effects on two out of five analysed characteristics. The results demonstrate that the use of autologous AT-MSCs is a successful approach to canine OA therapy.
\end{abstract}

Key words: Canine, osteoarthritis, mesenchymal stem cells, extended follow-up

Osteoarthritis (OA) is the most common form of joint disease. It is characterised by progressive degeneration of the articular cartilage, synovial inflammation, insufficient repair response that leads to cartilage loss, joint space narrowing and, finally, joint destruction (Elders, 2000; Guercio et al., 2012; Man and Mologhianu, 2014). OA is a major clinical problem in veterinary medicine, particularly for dogs, since it affects $\sim 20 \%$ of these animals (Guercio et al., 2012; Evans et al., 2013). Severe OA causes chronic pain, stiffness of the joint, degeneration and effusion, leading to significantly reduced joint function, lameness and

*Corresponding author; E-mail: gordnik@imgge.bg.ac.rs; Phone: 00381 (11) 397-6445; Fax: 00381 (11) 397-5808 
consequently to deterioration in the patient's quality of life (Pers and Jorgensen, 2013).

Despite the considerable efforts put into the development of effective pharmacological or surgical treatments, clinical success with respect to the prevention of cartilage matrix deterioration or cartilage restoration in OA remains elusive (Deschner et al., 2003; Verbruggen, 2006).

Mesenchymal stem cells (MSCs) have emerged as a promising alternative approach to treat cartilage disorders, mainly due to their regenerative and immunomodulatory properties (Arnhold and Wenisch, 2015; Zhang et al., 2016). These cells are ideal candidates for regenerative medicine, since they can be relatively easily harvested from their resident tissues, such as adipose tissue (AT) and bone marrow, and expanded in culture over several passages to reach sufficient numbers for clinical use. Also, upon implantation in sites of tissue damage, MSCs provide signals which favourably influence the activities of cells in the surrounding (Caplan and Dennis, 2006). All these properties make MSCs suitable for use as therapeutic agents in vivo, especially for regenerating damaged tissues in diseases of the locomotor system (Lavoie and Rosu-Myles, 2013).

The goal of this study was to evaluate the short- and long-term effects of the application of autologous MSCs from adipose tissue for the treatment of osteoarthritis in dogs.

\section{Materials and methods}

Animals

Ten canine patients with different joints showing the signs of osteoarthritis were included in the autologous AT-MSCs treatment. The degree of osteoarthritis was established based on the physical examination as follows: I - Reluctance of the animal to perform certain tasks or manoeuvres without obvious signs of stiffness or lameness; II - Lameness and stiffness occur after periods of sustained activity or after brief overexertion, and the clinical signs often disappear after several days; III - Most pronounced stiffness after periods of rest, and the animals appear to 'warm out' of their lameness or stiffness. Cold and damp weather often increases the severity of clinical signs; IV - Stiffness and lameness are fairly constant features, although the severity of signs may still be influenced by environmental factors. Affected animals may show signs of increased irritability and reclusiveness, and may snap or bite when approached or touched (Pedersen et al., 2000).

All patients completed the initial evaluation period of this study (up to 90 days after treatment). Also, for five of these patients an extended follow-up was performed (1-4 years after the initial evaluation period), marked as ' 1 year +' period. All patients' characteristics and diagnoses are presented in Table 1. One patient (no. 5) had additional diagnoses besides OA. Due to the fractures, this pa- 
tient developed irregular ankylosis of the carpometacarpal and intercarpal joints that led to the development of OA of the radiocarpal joint. Two patients (no. 4 and 11) died during the extended follow-up study due to diseases unrelated to MSCs treatment.

All dogs included in this study were client-owned animals. Adipose tissue collection and AT-MSCs therapy were approved and certified by the dog owners with a signed informed consent. AT collection was performed using anaesthetics, and AT-MSCs therapy was performed using sedatives, which excluded the pain, suffering, fear and stress of the animals, in accordance with the standards of good veterinary practice, the guidelines of good laboratory practice, Directive 2010/ 63/EU of the European Parliament and of the Council of 22 September 2009, as well as the European Convention for the protection of vertebrates intended for experimental and other scientific purposes (ETS 170).

\section{Isolation and culture of AT-MSCs for OA treatment}

Subcutaneous adipose tissue from the paralumbar region (on the borderline of the middle and the caudal lateral abdominal region) of each patient was collected by routine veterinary surgery procedures. Adipose tissue MSCs were isolated by collagenase digestion method as described previously (Zuk et al., 2002; $\mathrm{Yu}$ et al., 2011) and subsequently $6 \times 10^{4}$ cells per $\mathrm{cm}^{2}$ were seeded to the tissue culture flasks. Throughout the complete cultivation period, cells were grown in the medium containing $10 \%$ of autologous serum in an incubator at $37^{\circ} \mathrm{C}$ and $5 \% \mathrm{CO}_{2}$. After seeding, MSCs were allowed to adhere to the plastic surface of tissue culture dishes for seven days, at which point the medium was changed in order to remove unattached cells and debris. After this step, the medium was renewed every three days and cultivation continued until the number of cells reached the level of $>3 \times 10^{7}$. This number of cells resuspended in PBS was used for the injection in the symptomatic joint, or in the case of bilateral OA it was split in half.

\section{Differentiation of AT-MSCS}

Cells derived from adipose tissue and expanded in the growth medium with autologous serum were used for differentiation studies. For the control of stemness, the MSCs were cultured in appropriate differentiation media in order to obtain osteogenic and chondrogenic lineages. In these experiments the differentiation media were supplemented with $10 \%$ fetal calf serum. All studies were carried out with the same number of controls.

\section{Osteogenic differentiation}

Differentiation of isolated and cultured AT-MSCs toward osteogenic lineage and detection of extracellular calcium deposits by Alizarin Red S staining was 
performed as described here: http://www.promocell.com/fileadmin/knowledgebase/ pdf-xls/Osteogenic_Differentiation_and_Analysis_of_MSC.pdf. Accessed 15 November 2017, except for the osteogenic medium which was composed according to Mesimaki et al. (2009).

\section{Chondrogenic differentiation}

Differentiation toward chondrogenic lineage and Alcian blue staining of glycosaminoglycans was performed as described here: http://www.promocell.com/ fileadmin/knowledgebase/pdf-xls/Chondrogenic_Differentiation_and_Analysis of_MSC.pdf. Accessed 15 November 2017, except for the chondrogenic medium which was composed according to Vidal et al. (2008).

\section{Clinical evaluation}

Veterinary evaluation consisted of physical examination and assessment for lameness, pain on manipulation, range of motion of the joint and functional disability using a numeric rating scale at baseline and specified intervals. For all 10 dogs evaluation was performed up to 90 days after treatment (the initial evaluation period). Additionally, for 5 dogs evaluation was performed up to 4 years after the initial evaluation period (the extended follow-up). The clinical outcome measures were based on veterinary assessment using questionnaires and the numeric rating scale, which is presented in Table 2. Pain on manipulation was assessed by the combination of scores for palpation and joint manipulation, in which the motion of the joint was below its physiological limits of mobility. Range of motion of the joint assessment involved manipulation of the joint up to its physiological limits of mobility. In addition, for all dogs diagnosed with hip OA, during physical examination of the pain on manipulation, adduction, abduction and circumduction manipulations were performed (besides flexion and extension). None of the animals displayed pain during these three additional manipulations, and therefore they are not listed in Table 2.

\section{Statistical analysis}

Results were analysed using Wilcoxon signed-rank test. Two-sided $\mathrm{P}$ value was used and differences were considered to be significant when $\mathrm{P}<0.05$. The effect size ( $r$ ) was calculated and it was considered to be: $r=0.1$ - small effect; $r=0.3$ - medium effect; $r=0.5$ - large effect (Pallant, 2007). Data were analysed using the SPSS for Windows 20.0 software (IBM Corp., Armonk, NY, USA). 
SRZENTIĆ DRAŽILOV et al.

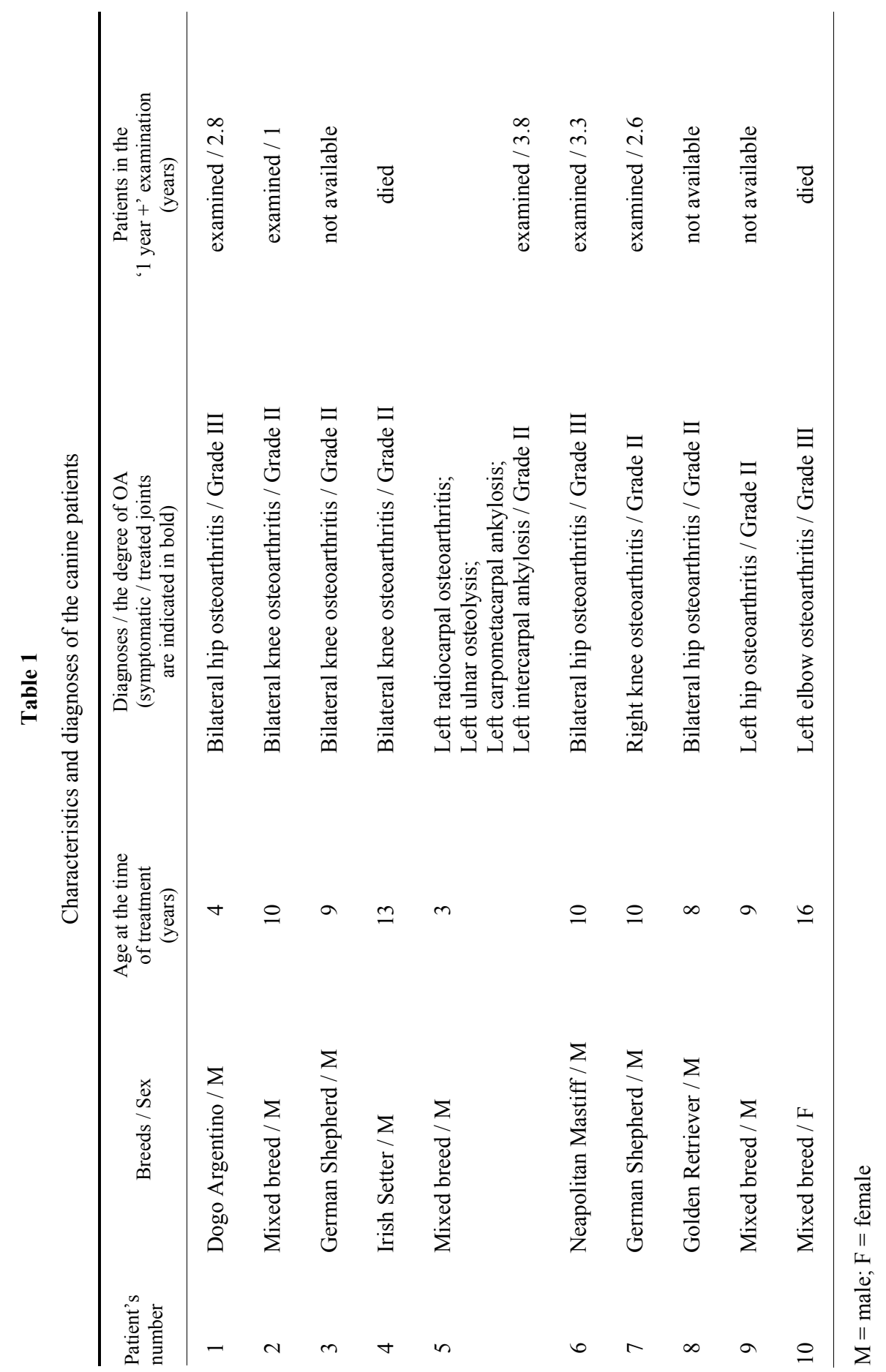


CANINE AT-MSCS FOR THE TREATMENT OF OSTEOARTHRITIS

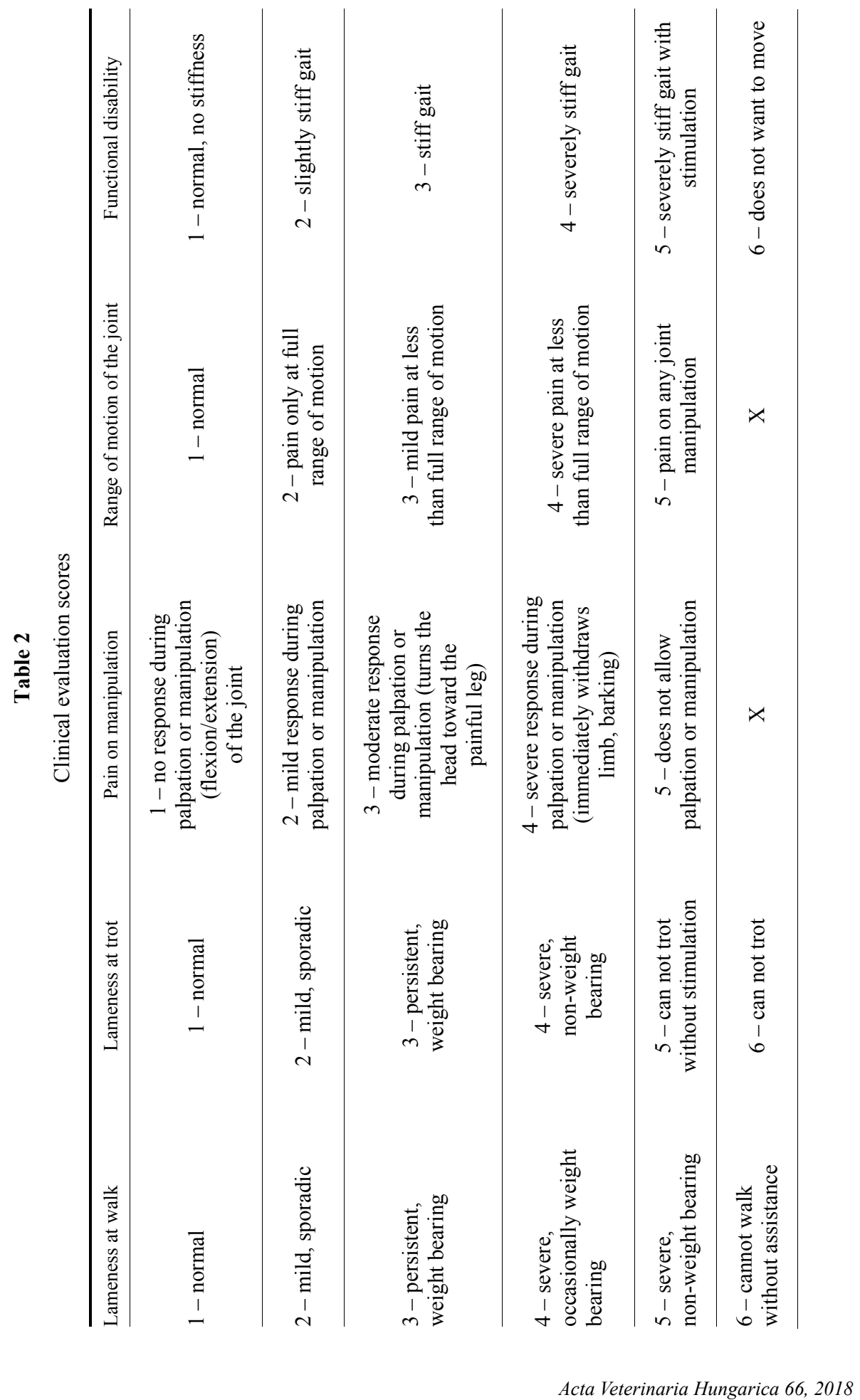




\section{Results}

\section{Differentiation of AT-MSCs}

Adipose tissue-MSCs were successfully isolated from all samples, showing the characteristic property to adhere to culture dishes and displaying fibroblast-like morphology. The stemness of isolated and cultured cells was confirmed by their ability to differentiate into osteo- and chondrocytic lineages. Cultivation of AT-MSCs in osteogenic medium led to the production of calcium deposits within their extracellular matrix, characteristic for osteoblasts, that was evidenced with Alizarin red S staining (Figs 1a and 1b). When AT-MSCs were grown in three-dimensional spheroid culture, only cells cultured in chondrogenic medium showed the presence of glycosaminoglycans, components of cartilage extracellular matrix, demonstrated by Alcian blue staining (Figs $2 a$ and $2 b$ ).

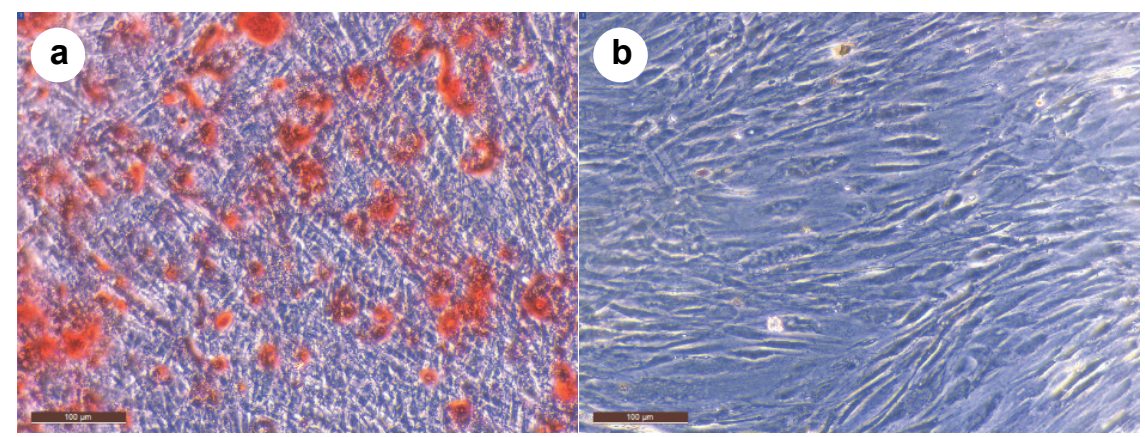

Fig. 1. Osteogenesis-induced differentiation of canine adipose tissue-derived mesenchymal stem cells (AT-MSCs). (a) AT-MSCs under osteogenic conditions for three weeks produced calcium-containing mineralised matrix as demonstrated by Alizarin red S dye incorporation; (b) no specific staining was observed in cultures maintained under control conditions. Magnification: $\times 10$, scale bar $=100 \mu \mathrm{m}$
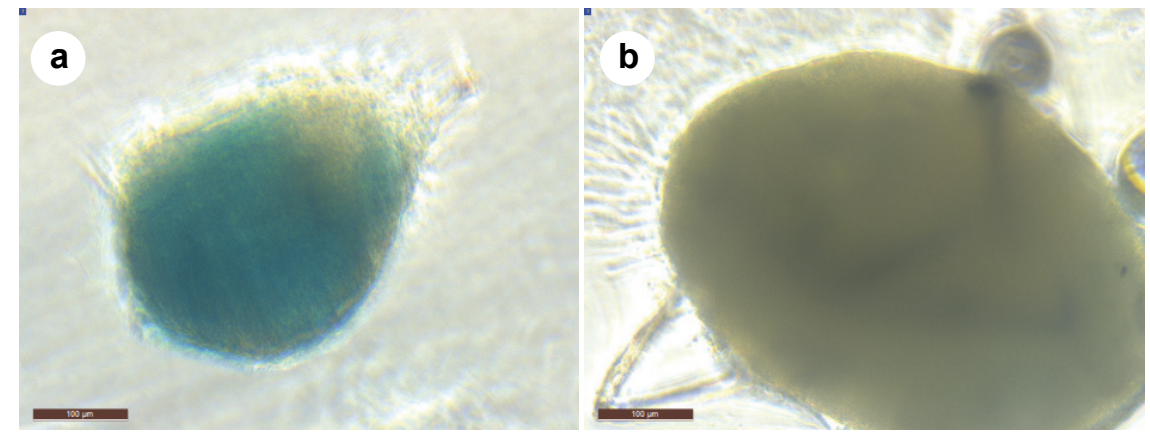

Fig. 2. Chondrogenesis-induced differentiation of canine AT-MSCs. (a) Specific Alcian blue staining of glycosaminoglycans produced by AT-MSCs in three-dimensional spheroid cultured under chondrogenic conditions for three weeks; (b) no specific staining was observed in cultures maintained under control conditions. Magnification: $\times 10$, scale bar $=100 \mu \mathrm{m}$ 


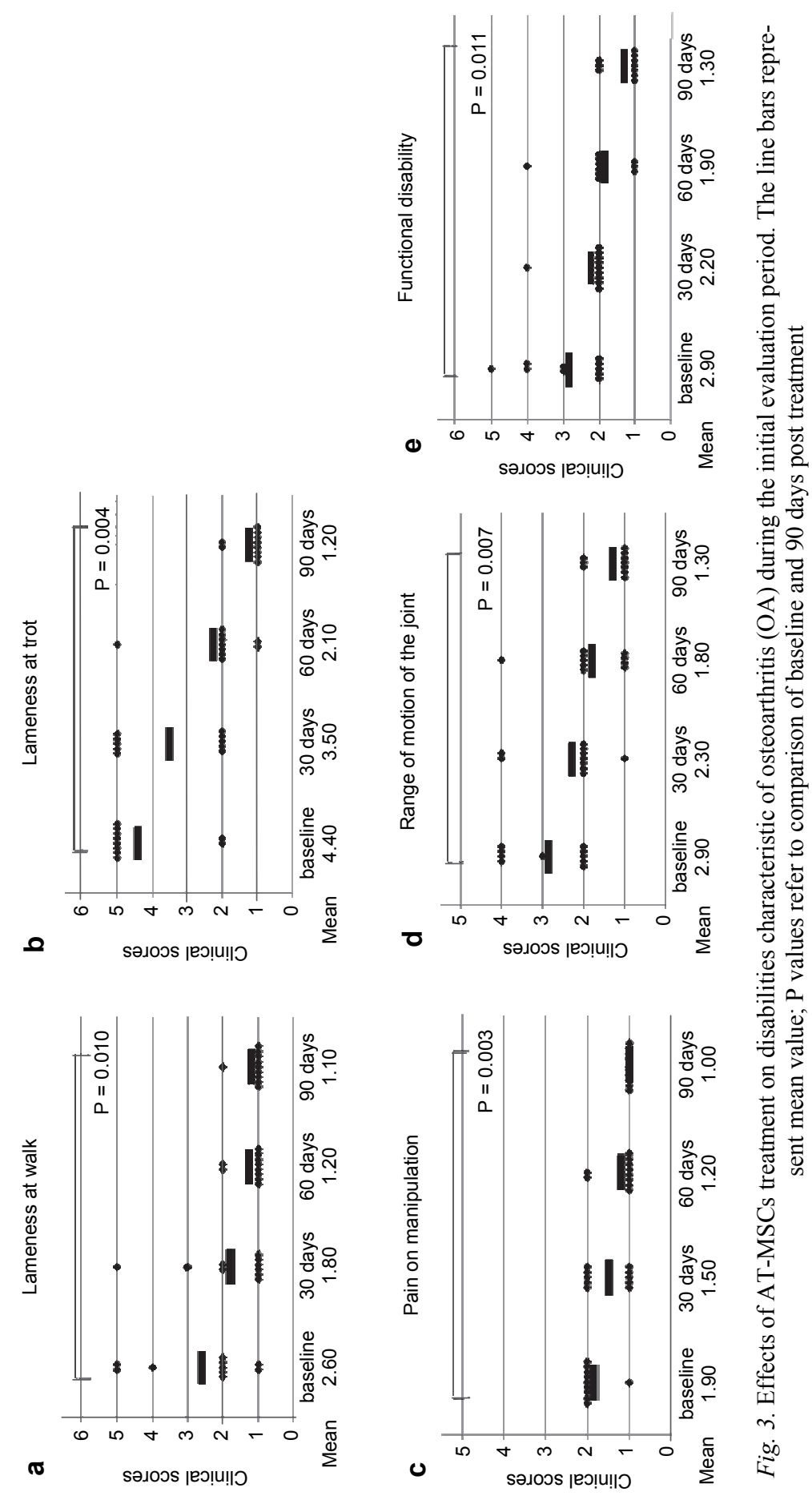




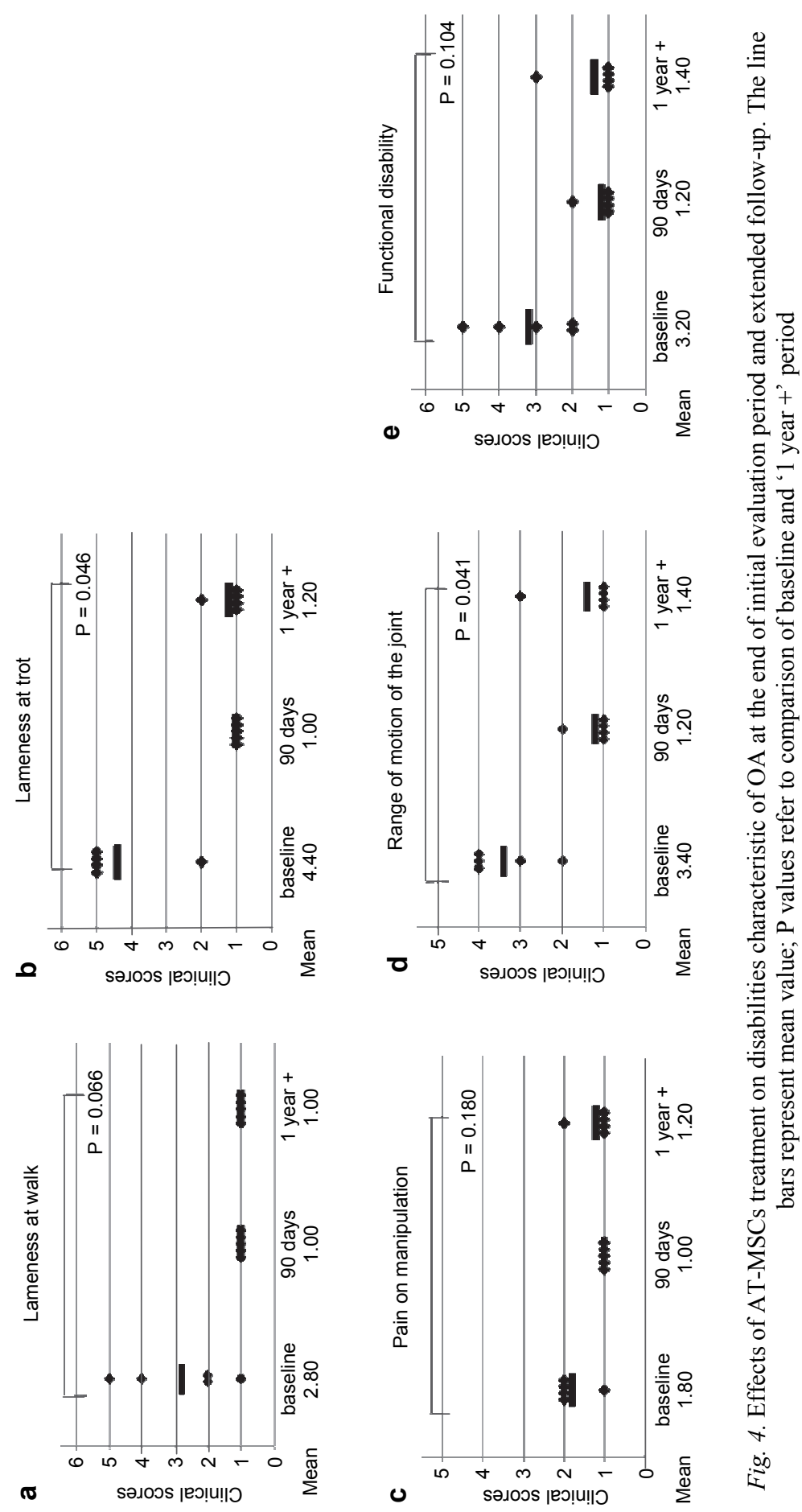




\section{Clinical evaluation}

All dogs completed the 90-day study, which was designated as the initial evaluation period. Comparison of scores of assessment at baseline and 90 days after AT-MSCs injection showed statistically significant improvement for all assessed impairments with a large effect size: lameness at walk $(\mathrm{P}=0.010, \mathrm{Z}=$ $-2.588, r=0.579)$ (Fig. 3a), lameness at trot $(P=0.004, Z=-2.873, r=0.643)$ (Fig. 3b), pain on manipulation ( $\mathrm{P}=0.003, \mathrm{Z}=-3.00, \mathrm{r}=0.671$ ) (Fig. 3c), range of motion of the joint $(P=0.007, Z=-2.701, r=0.604)$ (Fig. 3d), and functional disability $(\mathrm{P}=0.011, \mathrm{Z}=-2.546, \mathrm{r}=0.570)$ (Fig. 3e). Mean values of scores at these two evaluation points (baseline and 90 days post treatment) had dropped for all analysed characteristics (Fig. 3), with the biggest change detected for lameness at trot (from 4.40 to 1.20 ; Fig. 3b).

Regarding the extended follow-up study (the ' 1 year +' period), five out of ten patients were available for examination. When the results of evaluation were compared between baseline and the ' 1 year +' period, statistically significant improvement with a large effect size was detected for lameness at trot $(\mathrm{P}=0.046$, $\mathrm{Z}=-2.000, \mathrm{r}=0.632$ ) (Fig. $4 \mathrm{~b})$, and for the range of motion of the joint $(\mathrm{P}=$ $0.041, Z=-2.041, r=0.645$ ) (Fig. 4d). Statistically significant improvement was not detected for lameness at walk $(\mathrm{P}=0.066, \mathrm{Z}=-1.841, \mathrm{r}=0.582$ ) (Fig. 4a), pain on manipulation $(\mathrm{P}=0.180, \mathrm{Z}=-1.342, \mathrm{r}=0.424)$, (Fig. 4c), and functional disability $(\mathrm{P}=0.104, \mathrm{Z}=-1.625, \mathrm{r}=0.514)$ (Fig. 4e). Regarding the mean values of scores at these assessment points (baseline and ' 1 year + ' post treatment), the same trend was detected as after the initial evaluation period, i.e. values had dropped for all analysed characteristics (Fig. 4). Again, the biggest change was observed for lameness at trot that had changed from 4.40 to 1.20 (Fig. $4 \mathrm{~b}$ ). It is worth mentioning that between the end of the initial evaluation period and the " 1 year +' period only mild changes were observed in mean values of scores for all analysed characteristics.

\section{Discussion}

Articular cartilage lesions, as in OA, remain a major unsolved clinical problem in both veterinary and human medicine (Kong et al., 2017). One of the main characteristics of this pathology is the poor repair capacity of the affected tissue. Despite enormous research efforts in this field, no effective OAmodifying drug is currently available, as well as no conservative or operative treatments that would restore the articular cartilage integrity (de Bakker et al., 2013; Pers and Jorgensen, 2013; Kong et al., 2017). These shortcomings, accompanied by the increased spontaneous occurrence of articular cartilage defects in multiple joints in both animals (dogs in particular) and humans, have led to the increased interest in MSCs as a novel treatment option for this disease (de Bakker et al., 2013; Kong et al., 2017). In several preclinical studies with animal 
models of OA successful cartilage regeneration was reported after injection of MSCs into the damaged joint. For example, in the murine model of collagenaseinduced OA a single MSCs injection into the knee joint produced a significant decrease in synovitis score and cartilage damage (ter Huurne et al., 2012). Other studies using larger animal models of OA, such as rat (Horie et al., 2012), guinea pig (Sato et al., 2012), rabbit (Toghraie et al., 2012; Desando et al., 2013), goat (Murphy et al., 2003) and donkey (Mokbel et al., 2011) revealed similar results by applying MSCs.

Regarding dogs, the efficacy of MSCs therapy has been mainly reported for spontaneously occurring OA (de Bakker et al., 2013). Variation in the sample size and the duration of follow-up between studies is widely present. Improvement in outcome measures of the hip joints was reported following single intraarticular injection of autologous AT-MSCs for $18 \mathrm{dogs}$ with chronic OA after a period of three (Black et al., 2007) and six months (Cuervo et al., 2014) and for eight dogs after a period of six months (Vilar et al., 2013). Functional improvements in disabilities caused by chronic OA of the elbow joints was described for 14 dogs after a period of six months (Black et al., 2008) and for four dogs one month after treatment with autologous MSCs in either platelet-rich plasma or hyaluronic acid (HA) (Guercio et al., 2012). Using a follow-up period of one year, significant improvement in their disability was reported for the majority of 30 dogs with osteoarthritic elbow joints treated with allogeneic AT-MSCs in HA (Kriston-Pal et al., 2017). The common finding of all these studies is the significant improvement in scores for lameness, as well as improvements in pain and range of motion (Black et al., 2007, 2008; Guercio et al., 2012).

The results of our study concerning the initial evaluation period demonstrated that AT-MSCs therapy led to a statistically significant large improvement for all five assessed disabilities characteristic of OA. The biggest change was detected for lameness at trot, which is consistent with the majority of the published data. We would like to emphasise the results of the extended follow-up of this study, since, to the best of our knowledge, this is the longest follow-up of therapeutic outcomes related to the use of MSCs for the treatment of canine OA. A long-lasting positive effect was detected for two out of five analysed characteristics. Namely, for lameness at trot and for the range of motion of the joints, a statistically significant large improvement was shown even 1 to 4 years after the initial evaluation period. Also, as for the initial evaluation period, the biggest change was observed for lameness at trot. It is important to point out that there were no adverse effects detected in any patient throughout the complete evaluation period.

Thus, the obtained results demonstrate a successful canine OA therapy using autologous AT-MSCs and represent a contribution to current scientific studies in this area. In addition, the data gained in this study may influence the direction of AT-MSCs applications in humans. Namely, dogs are recognised to be a 
superior model to other commonly used species (such as rodents) based on disease mechanism, anatomical and clinical similarities to humans, and response to treatments (Chu et al., 2010; de Bakker et al., 2013). Consequently, the Osteoarthritis Research Society International (OARSI) recommended dogs as the appropriate model for studying the pathogenesis of OA and for the comparative and translational studies of OA (Cook et al., 2010). This is significant since twothirds of the aged human population are affected by different types of OA (Deschner et al., 2003; Verbruggen, 2006).

Some of the limitations of this type of scientific studies are the relatively small sample size of patients, and even more, the recruitment of patients for blinded, controlled trials (Black et al., 2008; Cuervo et al., 2014). This set-up is difficult to achieve, especially in veterinary science, for logistic and economic reasons (de Bakker et al., 2013). An additional limitation lies in the fact that functional evaluation scales, which are routinely used in human medicine, are not established in veterinary medicine. Namely, in the literature related to the use of MSCs in the treatment of OA in dogs, various approaches of clinical evaluation are described. For example, regarding the evaluation of the range of motion of the joint there are studies in which this parameter was assessed using goniometer (Cuervo et al., 2014; Vilar et al., 2016), while in other studies, as well as in our study, it was assessed using pain as an indicator (Black et al., 2007, 2008; Guercio et al., 2012). The latter approach has some limitations, since the pain in OA is a complex phenomenon composed of a number of different sensations from different sources (Salaffi et al., 2014). However, this approach is very informative, when it is coupled with pain on manipulation data obtained by evaluation methodology as described in the Materials and methods section. In spite of these limitations, the clinical use of MSCs in veterinary practice for commercial purposes has dramatically increased (Bernardo and Fibbe, 2013; Arnhold and Wenisch, 2015). Unfortunately, the number of published results regarding the efficacy of MSCs treatment is not following that trend. If available, data from these treatments, statistically validated to clinical or functional outcome measures, could help in the formulation of clear conclusions on the effectiveness of applied MSCs therapies (Jorgensen and Noel, 2012). Only by this approach would it be possible to correctly translate the potential therapeutic applications in veterinary and human medicine, thus providing a solid base for further research that will help in understanding the mechanisms by which MSCs promote tissue repair and regeneration.

\section{Acknowledgement}

This work was supported by the Ministry of Education, Science and Technological Development, Republic of Serbia (Grant No. III41004). 


\section{References}

Arnhold, S. and Wenisch, S. (2015): Adipose tissue derived mesenchymal stem cells for musculoskeletal repair in veterinary medicine. Am. J. Stem Cells 4, 1-12.

Bernardo, M. E. and Fibbe, W. E. (2013): Mesenchymal stromal cells: sensors and switchers of inflammation. Cell Stem Cell 13, 392-402.

Black, L. L., Gaynor, J., Adams, C., Dhupa, S., Sams, A. E., Taylor, R., Harman, S., Gingerich, D. A. and Harman, R. (2008): Effect of intraarticular injection of autologous adipose-derived mesenchymal stem and regenerative cells on clinical signs of chronic osteoarthritis of the elbow joint in dogs. Vet. Ther. 9, 192-200.

Black, L. L., Gaynor, J., Gahring, D., Adams, C., Aron, D., Harman, S., Gingerich, D. A. and Harman, R. (2007): Effect of adipose-derived mesenchymal stem and regenerative cells on lameness in dogs with chronic osteoarthritis of the coxofemoral joints: a randomized, double-blinded, multicenter, controlled trial. Vet. Ther. 8, 272-284.

Caplan, A. I. and Dennis, J. E. (2006): Mesenchymal stem cells as trophic mediators. J. Cell. Biochem. 98, 1076-1084.

Chu, C. R., Szczodry, M. and Bruno, S. (2010): Animal models for cartilage regeneration and repair. Tissue Eng. Part B Rev. 16, 105-115.

Cook, J. L., Kuroki, K., Visco, D., Pelletier, J. P., Schulz, L. and Lafeber, F. P. (2010): The OARSI histopathology initiative - recommendations for histological assessments of osteoarthritis in the dog. Osteoarthritis Cartilage 18, Suppl. 3, S66-79.

Cuervo, B., Rubio, M., Sopena, J., Dominguez, J. M., Vilar, J., Morales, M., Cugat, R. and Carrillo, J. M. (2014): Hip osteoarthritis in dogs: a randomized study using mesenchymal stem cells from adipose tissue and plasma rich in growth factors. Int. J. Mol. Sci. 15, 13437-13460.

de Bakker, E., Van Ryssen, B., De Schauwer, C. and Meyer, E. (2013): Canine mesenchymal stem cells: state of the art, perspectives as therapy for dogs and as a model for man. Vet. Q. 33, 225-233.

Desando, G., Cavallo, C., Sartoni, F., Martini, L., Parrilli, A., Veronesi, F., Fini, M., Giardino, R., Facchini, A. and Grigolo, B. (2013): Intra-articular delivery of adipose derived stromal cells attenuates osteoarthritis progression in an experimental rabbit model. Arthritis Res. Ther. 15, R22.

Deschner, J., Hofman, C. R., Piesco, N. P. and Agarwal, S. (2003): Signal transduction by mechanical strain in chondrocytes. Curr. Opin. Clin. Nutr. Metab. Care 6, 289-293.

Elders, M. J. (2000): The increasing impact of arthritis on public health. J. Rheumatol. Suppl. 60, 6-8.

Evans, C. H., Ghivizzani, S. C. and Robbins, P. D. (2013): Arthritis gene therapy and its tortuous path into the clinic. Transl. Res. 161, 205-216.

Guercio, A., Di Marco, P., Casella, S., Cannella, V., Russotto, L., Purpari, G., Di Bella, S. and Piccione, G. (2012): Production of canine mesenchymal stem cells from adipose tissue and their application in dogs with chronic osteoarthritis of the humeroradial joints. Cell Biol. Int. 36, 189-194.

Horie, M., Choi, H., Lee, R. H., Reger, R. L., Ylostalo, J., Muneta, T., Sekiya, I. and Prockop, D. J. (2012): Intra-articular injection of human mesenchymal stem cells (MSCs) promote rat meniscal regeneration by being activated to express Indian hedgehog that enhances expression of type II collagen. Osteoarthr. Cartil. 20, 1197-1207.

Jorgensen, C. and Noel, D. (2012): Mesenchymal stem cells in osteoarticular diseases: an update. Int. J. Mo1. Cell. Med. Winter Vol. 1, No 1.

Kong, L., Zheng, L. Z., Qin, L. and Ho, K. K. W. (2017): Role of mesenchymal stem cells in osteoarthritis treatment. J. Orthop. Translat. 9, 89-103.

Kriston-Pal, E., Czibula, A., Gyuris, Z., Balka, G., Seregi, A., Sukosd, F., Suth, M., Kiss-Toth, E., Haracska, L., Uher, F. and Monostori, E. (2017): Characterization and therapeutic application of canine adipose mesenchymal stem cells to treat elbow osteoarthritis. Can. J. Vet. Res. 81, 73-78. 
Lavoie, J. R. and Rosu-Myles, M. (2013): Uncovering the secrets of mesenchymal stem cells. Biochimie 95, 2212-2221.

Man, G. S. and Mologhianu, G. (2014): Osteoarthritis pathogenesis - a complex process that involves the entire joint. J. Med. Life 7, 37-41.

Mesimaki, K., Lindroos, B., Tornwall, J., Mauno, J., Lindqvist, C., Kontio, R., Miettinen, S. and Suuronen, R. (2009): Novel maxillary reconstruction with ectopic bone formation by GMP adipose stem cells. Int. J. Oral Maxillofac. Surg. 38, 201-209.

Mokbel, A. N., El Tookhy, O. S., Shamaa, A. A., Rashed, L. A., Sabry, D. and El Sayed, A. M. (2011): Homing and reparative effect of intra-articular injection of autologus mesenchymal stem cells in osteoarthritic animal model. BMC Musculoskelet. Disord. 12, 259.

Murphy, J. M., Fink, D. J., Hunziker, E. B. and Barry, F. P. (2003): Stem cell therapy in a caprine model of osteoarthritis. Arthritis Rheum. 48, 3464-3474.

Pallant, J. (2007). SPSS Survival Manual: A Step by Step Guide to Data Analysis Using SPSS for Windows Version 15. Open University Press, Milton Keynes, UK. pp. 223-225.

Pedersen, N. C., Morgan, J. P. and Vasseur, P. B. (2000). Joint diseases of dogs and cats. In: Ettinger, S. J. and Feldman, E. C. (eds) Textbook of Veterinary Internal Medicine: Diseases of the Dog and Cat. W. B. Saunders Company, Philadelphia, Pennsylvania. Volume 2, pp. 1862-1886.

Pers, Y. M. and Jorgensen, C. (2013): Mesenchymal stromal cells: updates and therapeutic outlook in rheumatic diseases. J. Clin. Med. 2, 201-213.

Salaffi, F., Ciapetti, A. and Carotti, M. (2014): The sources of pain in osteoarthritis: a pathophysiological review. Reumatismo 66, 57-71.

Sato, M., Uchida, K., Nakajima, H., Miyazaki, T., Guerrero, A. R., Watanabe, S., Roberts, S. and Baba, H. (2012): Direct transplantation of mesenchymal stem cells into the knee joints of Hartley strain guinea pigs with spontaneous osteoarthritis. Arthritis Res. Ther. 14, R31.

ter Huurne, M., Schelbergen, R., Blattes, R., Blom, A., de Munter, W., Grevers, L. C., Jeanson, J., Noel, D., Casteilla, L., Jorgensen, C., van den Berg, W. and van Lent, P. L. (2012): Antiinflammatory and chondroprotective effects of intraarticular injection of adipose-derived stem cells in experimental osteoarthritis. Arthritis Rheum. 64, 3604-3613.

Toghraie, F., Razmkhah, M., Gholipour, M. A., Faghih, Z., Chenari, N., Torabi Nezhad, S., Nazhvani Dehghani, S. and Ghaderi, A. (2012): Scaffold-free adipose-derived stem cells (ASCs) improve experimentally induced osteoarthritis in rabbits. Arch. Iran Med. 15, 495-499.

Verbruggen, G. (2006): Chondroprotective drugs in degenerative joint diseases. Rheumatology (Oxford) 45, 129-138.

Vidal, M. A., Robinson, S. O., Lopez, M. J., Paulsen, D. B., Borkhsenious, O., Johnson, J. R., Moore, R. M. and Gimble, J. M. (2008): Comparison of chondrogenic potential in equine mesenchymal stromal cells derived from adipose tissue and bone marrow. Vet. Surg. 37, 713-724.

Vilar, J. M., Cuervo, B., Rubio, M., Sopena, J., Dominguez, J. M., Santana, A. and Carrillo, J. M. (2016): Effect of intraarticular inoculation of mesenchymal stem cells in dogs with hip osteoarthritis by means of objective force platform gait analysis: concordance with numeric subjective scoring scales. BMC Vet. Res. 12, 223.

Vilar, J. M., Morales, M., Santana, A., Spinella, G., Rubio, M., Cuervo, B., Cugat, R. and Carrillo, J. M. (2013): Controlled, blinded force platform analysis of the effect of intraarticular injection of autologous adipose-derived mesenchymal stem cells associated to PRGFEndoret in osteoarthritic dogs. BMC Vet. Res. 9, 131.

Yu, G., Floyd, Z. E., Wu, X., Halvorsen, Y. D. and Gimble, J. M. (2011): Isolation of human adipose-derived stem cells from lipoaspirates. Methods Mol. Biol. 702, 17-27.

Zhang, W., Ouyang, H., Dass, C. R. and Xu, J. (2016): Current research on pharmacologic and regenerative therapies for osteoarthritis. Bone Res. 4, 15040.

Zuk, P. A., Zhu, M., Ashjian, P., De Ugarte, D. A., Huang, J. I., Mizuno, H., Alfonso, Z. C., Fraser, J. K., Benhaim, P. and Hedrick, M. H. (2002): Human adipose tissue is a source of multipotent stem cells. Mol. Biol. Cell 13, 4279-4295. 